\title{
Venous Thrombosis in Diabetes Mellitus
}

\author{
E. W. Jones and J. R. A. Mitchell \\ Department of Medicine, University Hospital, Queen's Medical Centre, Nottingham, UK
}

Summary. The incidence over 7 days of isotopically-detected calf and popliteal vein thrombosis was determined in a group of 60 diabetic patients admitted to hospital with myocardial infarction, heart failure or stroke, or for abdominal surgery. The result was compared with the incidence in 60 control subjects matched for age, sex and presenting diagnosis. Twentyone diabetic patients developed positive ${ }^{125}$ I-fibrinogen scans, compared with 19 control subjects; this difference is not sig- nificant. We conclude that diabetes is not associated with an enhanced risk of thrombosis in veins. It is therefore possible that the arterial and capillary abnormalities found in diabetes may arise from mechanisms other than a generalised thrombotic tendency.

Key words: Diabetes mellitus, venous thrombosis, ${ }^{125} \mathrm{I}$-fibrinogen.
Many patients with diabetes mellitus develop microvascular complications such as retinopathy and nephropathy [1]. In addition, it is generally agreed that diabetes mellitus is associated with an increased risk of large artery disease $[2,3]$. The mechanisms by which these vascular abnormalites arise are unknown. Abnormalities of haemostatic and coagulation mechanisms have been described in diabetes [4], and have been thought to indicate an 'increased thrombotic tendency'. Despite the great interest which has been shown in other aspects of diabetic vascular disease, little or nothing is known about the risk of venous thrombosis in diabetes $[5,6]$. It is not known whether there is a generalised tendency for thrombi to form in arteries, capillaries and veins, or whether the adverse effects of diabetes are confined to the arterial tree and capillary beds. If so, they may operate through mechanisms other than a generalised thrombotic tendency.

In view of this uncertainty, we decided to study prospectively the incidence of isotopically detectable leg vein thrombosis in a group of diabetic patients in the 7 days after admission to hospital or after operation. The results were compared with the incidence in a group of matched control subjects.

\section{Patients and Methods}

Patients over 40 years old, previously diagnosed as having diabetes, were considered for inclusion in the study when admitted to University Hospital, Nottingham, with a diagnosis of myocardial infarction, heart failure, or stroke with hemiparesis or hemiplegia, or for elective abdominal surgery. Patients were included irrespective of the type and duration of diabetes or the type and duration of treatment. Patients already on anticoagulant therapy were excluded as were amputees or patients with local leg lesions and those with a history of thyroid disease or of iodine sensitivity. As the study was of the 7-day incidence of isotopically detectable leg vein thrombosis, patients whose scans were negative, but who were not able to be scanned for the full 7 days because they died or were discharged from hospital, were withdrawn from the study. In addition, patients with negative scans who were started on anticoagulant therapy before the end of the 7 days (for reasons other than venous thromboembolism) were withdrawn.

When a diabetic patient had completed the study, the next nondiabetic patient of the same sex, within 5 years of the same age, and admitted with the same diagnosis, was entered into the control group. Reasons for exclusion and withdrawal were the same as for the diabetic group. If a control patient was withdrawn from the study, then the next suitable non-diabetic patient was entered, and so on, until each diabetic patient had been paired with a control patient matched for age, sex and admitting diagnosis.

Within $24 \mathrm{~h}$ of admission or of operation, patients were given an IV injection of $100 \mathrm{mg}$ sodium iodide followed by an IV injection of $100 \mu \mathrm{Ci}$ of ${ }^{125}$ I-labelled fibrinogen (Amersham International, Amersham, Bucks, UK). They were then given a week's course of potassium iodide tablets $(120 \mathrm{mg}$ twice daily) to block thyroid uptake of ${ }^{125} \mathrm{I}$.

Isotope scanning was carried out daily for 7 days with a Scaler and Ratemeter (Nuclear Enterprises, Reading UK) by the method described previously [7]. Scanning was confined to the popliteal fossa and calf because of the uncertainties of the method in the thigh [7]. A difference in fibrinogen uptake of $20 \%$ or greater between adjacent positions on the same leg, or between corresponding positions on the two legs, persisting for at least $24 \mathrm{~h}$, was considered a positive scan. If a positive scan was recorded, the clinicians in charge of the case were informed and decisions about therapy were left to their clinical judgement. Detailed clinical records of all patients entered into the study were maintained. 
Table 1. Reasons for withdrawal after entry into the study

\begin{tabular}{lcc}
\hline & $\begin{array}{l}\text { Diabetic } \\
\text { patients }\end{array}$ & $\begin{array}{l}\text { Control } \\
\text { subjects }\end{array}$ \\
\hline Discharge before 7 days & 11 & 23 \\
Died before 7 days & 9 & 6 \\
Anticoagulated before 7 days & 5 & 7 \\
Other reasons for withdrawal & 2 & 2 \\
Total & 27 & 38 \\
Number of days scanned before & $3.2 \pm 0.4$ & $3.5 \pm 0.3$ \\
$\quad$ withdrawal (mean \pm SEM) & & \\
\hline
\end{tabular}

All these patients had negative isotope scans up to the day of withdrawal

The study had been approved by the local Ethical Committee, and full informed consent was obtained from all patients and control subjects.

\section{Statistical Analysis}

Results are given as mean \pm SEM. Statistical comparison between diabetic patients and matched control subjects at entry into the study was by means of a paired t-test. The results were analysed using the Chi-squared test after applying Yates' correction.

\section{Results}

Eighty-seven diabetic patients and 98 control subjects entered into the study. Twenty-seven of the diabetic and 38 control subjects were withdrawn, leaving 60 pairs of diabetic patients and matched control subjects who completed the 7 day study. Reasons for withdrawal are given in Table 1.

Clinical details of these 60 pairs, before admission, are given in Table 2. They appear to be well matched not only for age, sex and admitting diagnosis (as was intended from the design of the study), but also for other clinical variables which may be important in modifying the risk of venous thrombosis. The diabetic patients were, however, significantly heavier than the control subjects (weight/height ${ }^{2}$ (mean \pm SEM); diabetic patients: $25.4 \pm 0.5 \mathrm{~kg} / \mathrm{cm}^{2}$; control subjects: $23.2 \pm 0.5 \mathrm{~kg}$ / $\mathrm{cm}^{2} ; p<0.01$, paired t-test). There was no difference between the two groups in terms of initial haemoglobin levels, packed cell volume, white cell count or platelet count.

The progress of the patients after hospital admission is summarised in Table 3. Again, there are no major dissimilarities between the two groups in terms of clinical factors which may modify the risk of developing deep venous thrombosis.

Twenty-one of the diabetic patients (35\%) developed positive scans within the 7 days, as did $19(32 \%)$ of the control subjects (NS). Positive scans occurred in both calves in four of the diabetic and three of the control subjects and in one calf in 17 diabetic and 16 control subjects. There was no difference in the timing of
Table 2. Clinical details on admission of patients who completed study

\begin{tabular}{|c|c|c|}
\hline & $\begin{array}{l}\text { Diabetic } \\
\text { patients } \\
(n=60)\end{array}$ & $\begin{array}{l}\text { Control } \\
\text { subjects } \\
(n=60)\end{array}$ \\
\hline Age (years) & $66 \pm 9$ & $66 \pm 9$ \\
\hline Weight (kg) & $66.9 \pm 1.7$ & $63.9 \pm 1.7$ \\
\hline Height $(\mathrm{cm})$ & $165 \pm 1.3$ & $166 \pm 1.0$ \\
\hline Weight $/$ height ${ }^{2}\left(\mathrm{~kg} / \mathrm{cm}^{2}\right)$ & $25.4 \pm 0.5$ & $23.2 \pm 0.5$ \\
\hline Sex ratio (male: female) & $25: 35$ & $25: 35$ \\
\hline \multicolumn{3}{|l|}{ Diagnosis } \\
\hline \multicolumn{3}{|l|}{ Number of patients with: } \\
\hline Myocardial infarction & 30 & 30 \\
\hline Heart failure & 12 & 12 \\
\hline Stroke & 14 & 14 \\
\hline Surgery & 4 & 4 \\
\hline \multicolumn{3}{|l|}{ Previous History } \\
\hline \multicolumn{3}{|l|}{ Number of patients with: } \\
\hline Varicose veins & 10 & 12 \\
\hline $\begin{array}{l}\text { Deep vein thrombosis and/or } \\
\text { pulmonary embolus }\end{array}$ & 2 & 4 \\
\hline $\begin{array}{l}\text { Number of current } \\
\text { cigarette smokers }\end{array}$ & 14 & 15 \\
\hline \multicolumn{3}{|l|}{ Treatment Before Admission } \\
\hline \multicolumn{3}{|l|}{ Number of patients taking: } \\
\hline Anti-inflammatory drugs & 1 & 1 \\
\hline $\begin{array}{l}\text { Anti-dysrhythmics } \\
\text { (including Digoxin) }\end{array}$ & 16 & 14 \\
\hline Antibiotics & 1 & 4 \\
\hline Hypotensives & 8 & 11 \\
\hline Diuretics & 27 & 22 \\
\hline Other drugs & 22 & 23 \\
\hline $\begin{array}{l}\text { Average immobility } \\
\text { before admission (days) }\end{array}$ & 2.8 & 2.2 \\
\hline
\end{tabular}

Results are expressed as mean \pm SEM

the first positive scan in either group (diabetic patients: $3.1 \pm 0.7$ days; control subjects: $3.2 \pm 0.7$ days). The extent of thrombosis as determined by maximum number of 'hot spots' did not differ between the two groups (number of 'hot spots': diabetic patients: $2.1 \pm 0.3$; control subjects: $2.0 \pm 0.3$ ).

Although the number of withdrawals was greater in the control than in the diabetic group, this difference was not significant ( $p>0.1$, Chi-squared test). However, in order not to miss any bias that might have been introduced because of the withdrawals, we also analysed the results on a pragmatic ('intention to scan') basis. Positive scans developed in 21 of 87 diabetic patients entered into the study ( $24 \%$ ) and in 19 of 98 control subjects $(19 \%)$ entered. This difference is not significant ( $p>0.1$, Chi-squared test).

Table 4 shows a comparison between the diabetic patients who developed positive scans and those who did not. Development of deep vein thrombosis was not related to duration of diabetes or its treatment. There was no correlation with the presence of complications of diabetes before admission or with the development of complications related to the diabetes after admission. 
Table 3. Progress after admission in patients who completed the study

\begin{tabular}{lcc}
\hline & $\begin{array}{c}\text { Diabetic } \\
\text { patients } \\
(n=60)\end{array}$ & $\begin{array}{c}\text { Control } \\
\text { subjects } \\
(n=60)\end{array}$ \\
\hline Final Diagnosis & & \\
Uncomplicated myocardial infarction & 14 & 15 \\
Myocardial infarction complicated & & \\
$\quad$ by heart failure or dysrhythmia & 16 & 15 \\
Left ventricular failure & 5 & 6 \\
Congestive cardiac failure & 7 & 6 \\
Left hemiparesis & 7 & 8 \\
Right hemiparesis & 7 & 6 \\
Surgery (benign pathology) & 3 & 3 \\
Surgery (malignant pathology) & 1 & 1 \\
Drugs After Admission & & \\
Opiates & 28 & 28 \\
Antibiotics & 9 & 10 \\
Anti-inflammatory & 2 & 8 \\
Diuretic & 36 & 32 \\
Digoxin & 9 & 9 \\
Other drugs & 35 & 38 \\
Fluids After Admission & & \\
Blood & 1 & 0 \\
Dextrose & 5 & 6 \\
Saline & 4 & 5 \\
Plasma & 0 & 1 \\
Dextran & 2 & 1 \\
Mean duration of bed rest (days) & 3.30 & 3.36 \\
\hline
\end{tabular}

\section{Discussion}

In the search for the cause of the vascular complications of diabetes, workers have demonstrated abnormalities of the coagulation system $[4,8]$, the haemostatic system [9], prostaglandin metabolism [10,11] and of fibrinolysis $[4,12]$, all of which might suggest that diabetes is associated with an increased risk of thrombosis. This has been put forward as a possible underlying mechanism for the abnormalities of arteries and capillaries commonly associated with diabetes.

Many of the abnormalities described could also be thought of as increasing the risk of venous thrombosis, yet there is no evidence that diabetic patients are more prone to venous thromboembolism than normal subjects. Some studies have indeed suggested that the converse may be true and that venous thromboembolism may be less common amongst diabetic than normal subjects. In a 5-year follow-up study of 53 diabetic patients with strokes, compared with 53 non-diabetic patients matched for age, sex, and diagnosis of cerebrovascular disease, the incidence of fatal pulmonary embolism recorded in the diabetic group was $7 \%$ of 42 deaths, compared with $21 \%$ of 33 deaths in the matched control group [13]. The results were based on autopsy evidence in approximately two-thirds of the cases in both groups, but it is possible that death was less likely to be ascribed to pulmonary embolus in the diabetic
Table 4. Comparison between diabetic patients with positive scans and those with negative scans

\begin{tabular}{lll}
\hline & \multicolumn{2}{l}{ Scans } \\
\cline { 2 - 3 } & $\begin{array}{l}\text { Positive } \\
(n=21)\end{array}$ & $\begin{array}{l}\text { Negative } \\
(n=39)\end{array}$ \\
\hline Known duration of diabetes (years) & $6.7 \pm 4.1$ & $8.2 \pm 5.0$ \\
Treatment Before Admission & & \\
Insulin & 2 & 9 \\
Biguanide & 1 & 2 \\
Sulphonylurea & 10 & 16 \\
Combination & & \\
$\quad$ biguanide/sulphonylurea & 0 & 2 \\
Diet alone & 8 & 10 \\
Complications Before Admission & & \\
Retinopathy & 5 & 12 \\
Neuropathy & 3 & 8 \\
Nephropathy & 2 & 1 \\
Intermittent claudication & 6 & 7 \\
Complications After Admission & & \\
Ketoacidosis & 4 & 9 \\
Hypoglycaemia & 1 & 1 \\
Age (years) & $68 \pm 10$ & $65 \pm 11$ \\
Weight/height ${ }^{2}$ (kg/cm ${ }^{2}$ ) & $25.5 \pm 4.1$ & $25.5 \pm 4.2$ \\
\hline Result are expressedas mean \pm SEM & &
\end{tabular}

Results are expressed as mean \pm SEM

group because of the known association of diabetes with other possible candidates for the cause of death, such as cardiovascular and cerebrovascular disease.

In another study of 258 diabetic patients after myocardial infarction [14], only seven (2.7\%) experienced clinically diagnosed pulmonary emobli, a much smaller figure than would have been anticipated in non-diabetic patients in the same conditions. In the same study, an autopsy was carried out on 77 of those patients who died. Pulmonary emboli were found in only four patients and considered to be the cause of death in only one. In contrast, autopsy studies of non-diabetic patients have suggested a prevalence of pulmonary embolus as high as $27.2 \%$ in patients dying after myocardial infarction [15]. It is possible, however, that the risk of venous thromboembolism in diabetic patients is masked in studies such as these as diabetic patients are at greater risk of dying of complications of the initial myocardial infarction, and death may therefore occur before significant venous thrombosis has occurred.

In the present study, we attempted to determine the incidence of venous thrombosis in a group of diabetic patients at substantial risk by virtue of their age and underlying illness. The results were compared with the incidence in a similarly 'at-risk' group of normal subjects. Known risk factors for venous thrombosis were similar in both groups of patients, with the exception of weight - the diabetic patients tended to be heavier than the control subjects, and this should have increased their likelihood of developing deep vein thrombosis [16]. We found no significant difference in the incidence of iso- 
topically detected calf and popliteal vein thrombosis between the two groups. This was true when the results were analysed both as a direct comparison between the matched groups of diabetic and control patients, and when analysed on a 'pragmatic' basis, taking into account the withdrawals from the study in both groups. We found no association between the development of deep vein thrombosis in the diabetic group and the presence of pre-existing vascular complications of diabetes, or the development of complications associated with the diabetes during the period of study. The duration of diabetes and its treatment similarly made no difference to the risk of developing deep vein thrombosis.

The results of this study would suggest that diabetes is not associated with an enhanced risk of thrombosis in veins. It is possible that the increased risk of death from arterial disease in diabetics may not be due to an increased thrombotic tendency, but could be due to other mechanisms, such as the effect of the disease on the arterial wall (eg. by accelerating the atheromatous process), or effects on the target organ (by altering the rate of dysrhythmias or pump failure in myocardial infarction, for example). Similarly, the capillary abnormalities in diabetes may be the result of changes which have been demonstrated such as thickening of the basement membrane of the capillary endothelium [17], rather than microthrombotic capillary occlusion.

Acknowledgements. Dr. E. W.Jones was supported by a project grant from the Medical Research Council. Purchase of ${ }^{125}$ I-fibrinogen was made possible by the receipt of one of the Edith Walsh and Geoffrey Holt awards from the Board of Science and Education of the British Medical Association. We thank the physicians and surgeons of the University Hospital, Nottingham for kindly allowing access to patients under their care. Mrs. E. Holland shared the burden of the 'legwork', and without her help, the study would not have been possible.

\section{References}

1. West KM (1982) Hyperglycaemia as a cause of long term complications. In: Keen $\mathbf{H}$, Jarrett $\mathbf{J}$ (eds) Complications of diabetes, 2nd edn. Edward Arnold, London, pp 13-18
2. Kannel WB, McGee DL (1979) Diabetes and cardiovascular disease - the Framingham study. JAMA 241: 2035-2038

3. Keen H, Rose GA, Pyke DA, Boyns DR, Chlouverakis C, Mistry S (1965) Blood sugar and arterial disease. Lancet 2: 505-508

4. Fuller JH, Keen H, Jarrett RJ, Omer T, Meade TW, Chakrabarti R, North WRS, Stirling Y (1979) Haemostatic variables associated with diabetes and its complications. Br Med J 2: 964-966

5. Bradley RF (1971) Cardiovascular disease. In: Marble A, White P, Bradley RF, Krall LP (eds) Joslin's diabetes mellitus, 11th edn. Lea and Febiger, Philadelphia, pp 449

6. Masi AT (1972) Endocrine factors and risk of venous thrombosis. Milbank Mem Fund Q 50: 46-59

7. Morris GK, Mitchell JRA (1977) Evaluation of ${ }^{125} \mathrm{I}$-fibrinogen in patients with hip fractures; comparison between isotope scanning and necropsy findings. Br Med J 1: 264-266

8. Egeberg O (1963) The blood coagulability in diabetic patients. Scand J Clin Lab Invest 15: 533-538

9. Mustard JF, Packham MA (1977) Platelets and diabetes mellitus. N Engl J Med 297: 1345-1347

10. Halushka PV, Rogers RC, Loadholt CB, Colwell JA (1981) Increased platelet thromboxane synthesis in diabetes mellitus. J Lab Clin Med 97: 87-96

11. Silberbauer K, Clopath P, Sinziger H, Schernthaner G (1979) Decreased vascular prostacyclin in juvenile onset diabetes. $\mathrm{N}$ Engl $\mathbf{J}$ Med 300: 366-367

12. Fearnley GR, Chakrabarti R, Avis PRD (1963) Blood fibrinolytic activity in diabetes mellitus and its bearing on ischaemic heart disease. Br Med J 1: 921-923

13. Asplund K, Hagg E, Helmers C, Lithner F, Strand T, Wester PO (1980) The natural history of stroke in diabetic patients. Acta Med Scand 207: 417-424

14. Partamian JO, Bradley RF (1965) Acute myocardial infarction in 258 cases of diabetes: immediate mortality and five year survival. N Eng1 J Med 273: 455-461

15. Coon WW, Coller FA (1959) Some epidemiological considerations of thromboembolism. Surg Gynaecol Obstet 109: 487-501

16. Clayton JK, Anderson JA, McNicol GP (1976) Pre-operative prediction of post-operative deep vein thrombosis. Br Med $\mathrm{J} 2$ : 910-912

17. Ashton N (1974) Vascular basement membrane changes in diabetic retinopathy. $\mathrm{Br} \mathrm{J}$ Ophthalmol 58: 344-366

Received: 17 January 1983

and in revised form: 27 June 1983

Dr. E. W. Jones

Department of Medicine

Queen's Medical Centre

Nottingham, UK 